\title{
Radiation Dose Volume Effects in the Lung
}

\author{
Lawrence B. Marks, M.D. , Soren M. Bentzen, D.Sc. ${ }^{\ddagger}$, Joseph O. Deasy, Ph.D.\#, Feng-Ming \\ (Spring) Kong, M.D., Ph.D. $\$$, Jeffrey D. Bradley, M.D. ${ }^{\#}$, Ivan S. Vogelius, Ph.D. ${ }^{*}$, Issam EI \\ Naqa, Ph.D.\#, Jessica L. Hubbs, M.S. ${ }^{*}$, Joos V. Lebesque, M.D., Ph.D. ${ }^{£}$, Robert D. \\ Timmerman, M.D. ${ }^{\S}$, Mary K. Martel, Ph.D. ${ }^{\wedge}$, and Andrew Jackson, Ph.D.\&
}

* Department of Radiation Oncology, University of North Carolina, Chapel Hill, NC $¥$ Departments of Human Oncology, University of Wisconsin School of Medicine, Madison, WI \# Department of Radiation Oncology, Alvin J. Siteman Cancer Center, Washington University School of Medicine, St. Louis, MO $\$$ Department of Radiation Oncology, University of Michigan, Ann Arbor, MI ₹ Department of Radiation Oncology, The Netherlands Cancer Institute, Antoni van Leeuwenhoek Hospital, Amsterdam, The Netherlands § Department of Radiation Oncology, University of Texas Southwestern, Dallas, $\mathrm{TX}^{\wedge}$ Department of Radiation Physics, M.D. Anderson Cancer Center, Houston, TX \& Medical Physics, Memorial Sloan Kettering Cancer Center, New York, NY

\begin{abstract}
The three dimensional dose/volume/outcome data for lung are reviewed in detail. The rate of symptomatic pneumonitis is related to many dosimetric parameters, and there are no evident threshold "tolerance dose/volume" levels. There are strong volume and fractionation effects.
\end{abstract}

\section{Keywords}

Lung injury; radiation; QUANTEC; pneumonitis

\section{Clinical significance}

\begin{abstract}
Radiation therapy (RT) plays an important role in the treatment of several tumors in and around the thorax. Clinically-significant symptomatic pneumonitis (RP) occurs in $\approx 5-50 \%$, $\approx 5-10 \%$, and $\approx 1-5 \%$ of patients irradiated for cancers of the lung, mediastinal lymphatics, and breast, respectively $(1,2)$, and is one of the most common clinical toxicities in these patients. The risk of RP limits the delivered dose for some and may thus hamper tumor control. A large fraction of patients experience sub-clinical RT-induced injury (e.g., reductions in formal pulmonary function tests [PFTs], and/or radiologic changes) that may be chronic and reduce the patient's reserve to deal with future cardio-pulmonary stresses.
\end{abstract}

Correspondence \& Reprints: Lawrence B. Marks, M.D., Department of Radiation Oncology, Box 7512 University of North Carolina, Chapel Hill, NC 27514, Tel: 919-966-0400, Fax: 919-966-7681, marks@ med.unc.edu.

Conflict of Interest: The authors report no conflicts.

Publisher's Disclaimer: This is a PDF file of an unedited manuscript that has been accepted for publication. As a service to our customers we are providing this early version of the manuscript. The manuscript will undergo copyediting, typesetting, and review of the resulting proof before it is published in its final citable form. Please note that during the production process errors may be discovered which could affect the content, and all legal disclaimers that apply to the journal pertain. 


\section{Endpoints}

Several endpoints can be used to define RT-induced lung injury (Table 1). In the context of QUANTEC, consideration is limited to the endpoint of symptoms; arguably the most clinically meaningful endpoint for patients. Approximately $80 \%$ of RP is clinically manifest within 10 months of RT. The scoring of symptomatic RP presents several challenges:

a. Dyspnea is non-specific and can also be caused by anemia, cardiac arrhythmia, infection, tumor, etc. In a prospective clinical study, 28\% of patients suspected of having RP also had ongoing medical conditions confounding the diagnosis (3).

b. Toxicity grading systems often consider the medical interventions (e.g., steroid use). Therefore, physicians that are more apt to prescribe steroids may note a higher reported rate of pneumonitis. Steroid use is grade 3 for RTOG, but grade 2 in several other systems. Requirement of steroids has been omitted from the CTCAE 3.0.

c. Treatment-induced tumor shrinkage may improve overall lung function (especially for central lesions compressing regional airways/vessels), thus maybe masking the effects of RT on the normal lung.

d. The relevant grade of symptoms is controversial. Grade I RP is common, and is often not clinically significant. More severe RP is more clinically relevant, but its lower incidence limits the statistical power of analysis based on severe events.

\section{Challenges Defining Volumes}

The lung is usually considered as a single, paired-organ (total lung tissue) rather than as separate ipsi- and contra-lateral lungs. Since lung volumes vary with breathing, there is ambiguity in defining its DVH-based parameters. In the articles herein reviewed, dosimetric information was mostly based on CT images obtained during free breathing. The dosimetric parameters would change had these scans been obtained at specific phases of the respiratory cycle. Segmentation of a thoracic scan can be challenging. There is uncertainty defining how much of the bronchus should be defined as "lung", and the lung edges may vary with the window/level setting. Thus, volume-based parameters will vary between investigators. The accuracy of any auto-segmenting tools should be carefully assessed, especially to ensure that portions of atelectatic lung or tumor at soft tissue interfaces are not inadvertently omitted from the lung.

During RT planning, the total lung volume is usually defined to exclude the gross tumor volume (GTV). Excluding the planning target volume (PTV), rather than the GTV from the lung volume, may reduce the apparent lung exposure (as normal lung within the PTV, but outside the GTV, will be excluded), and may increase inter-institutional variations (as PTV margins may vary).

During treatment, there may be changes in GTV-volume, with corresponding changes in normal tissue anatomy. Thus, plans defined based on pre-RT imaging may not accurately reflect the degree of normal lung exposure. While this effect has not been systematically assessed, presumably tumor shrinkage (with movement of normal lung into to previouslyoccupied GTV) will increase normal lung exposure relative to pre-RT plans. Similarly, changes in pleural effusions, and re-aeration of lung regions can cause anatomic and functional changes. Indeed, the ability to predict changes in lung function based on pre-RT dosimetric data is reduced in patients with tumor-associated airway obstruction (i.e., those most likely to experience re-aeration during therapy) (4). 


\section{Review of dose/volume data}

The literature on dose-volume-pneumonitis is extensive: for this review we identified $>70$ published papers. The results are inconsistent, both for the best predictive metrics and significant co-morbid factors.

\subsection{Lyman-Kutcher-Burman (LKB) DVH-reduction scheme and Mean Lung Dose (MLD)}

The most widely used NTCP model for RP is the LKB model. This model has three parameters, a position parameter, $\mathrm{TD}_{50}$, a steepness parameter, $m$, and the volume exponent, $n$ (where $n=1$ the model reverts to mean lung dose; MLD). While TD50 is strongly dependent on the grade of RP being considered, $\mathrm{n}$ is often regarded as a tissue characteristic. Figure 1 shows a meta-analysis of reported n-values, it does not include the study by Rancati (39), which used only the ipsilateral lung. The best estimate for $n$ is 1.03 with standard deviation 0.17 (95\% conf interval: [0.67-1.39]), the test for heterogeneity of the data sets is not significant, and $\mathrm{I}^{2}$ is zero. The TD50 values cannot be pooled in a meaningful way, as the various reports analyzed considered varying grades of RP.

The MLD model is widely considered due to its simplicity and effectiveness. It was the metric used by the large multi-institutional analysis of Kwa (5), and often performs as well as more complex models. Figure 2A shows a logistic regression fitted to RP vs. MLD data from all published studies of a significant size that had extractable complication rates binned by mean dose. Some of the variation around the fitted curve is possibly explained by differences in patient selection as well as differences in the grade of RP reported in the various studies. Nevertheless, there is a relatively small 68\% confidence interval (stippled lines). A similar fit using the probit model (equivalent to fitting the Lyman model with $\mathrm{n}$ fixed at 1) gives an essentially identical response function in the region of the data. The gradual increase in dose response suggests that there is no absolute 'safe' mean lung dose below which there is no pneumonitis. The clinically acceptable risk of RP -and therefore the associated planning constraint on MLD- will depend on the risk: benefit ratio in the individual case. A number of non-DVH-based factors may affect the risk of RP (section 5). Finally, it is likely that the MLD-RP relationship may have lower predictive power for "nonstandard' dose distributions not included in these analyses, for example after stereotactic body radiotherapy (SBRT) or proton therapy.

\subsection{Dose-volume threshold analyses}

Various Vx values (\% lung volume receiving $\geq X$ Gy) are associated with RP risk (Fig. 2b) The observation that a variety of dose levels are predictive suggests that there is no sharp dose threshold, below which there is no risk. Within individual data sets, there are usually strong correlations between the different dosimetric parameters (e.g., V5 and V20); and thus there are probably no "optimal" thresholds. Further, the correlations between dosimetric parameters are technique dependent, and readers should carefully assess the similarity of their treatment technique before using any of these limits as clinical constraints.

RT-induced dyspnea appears more commonly in patients with lower- vs. upper-lobe tumors, and may be better correlated with RT doses to the lower- vs. upper-lung (7-11). An analysis that combined institutional data with RTOG 93-11 (n=324) concluded that RP is much better predicted (at least for that dataset) based on mean lung dose and positional dependence of the high dose region as opposed to mean lung dose alone (12). The cause of this correlation is presently unknown and requires further investigation. 


\section{Factors affecting risk}

Several patient and treatment-related factors have been inconsistently reported to correlate with the risk of developing RP. Vogelius and Bentzen (70) applied standard meta-analysis methodology to eight factors with meaningful data. In summary, there was no significant evidence for an association between RP and laterality (left vs. right lung), co-morbidity or gender. Younger patients, typically defined as $<60$ or $<70$ years of age, have a lower risk of RP than older patients. Surgery had a just-significant p-value, but the test for heterogeneity was significant $(\mathrm{p}=0.03)$ suggesting that the variation among studies cannot be explained by chance alone. Thus, at present, the reduced rate of RP in patients undergoing surgery remains controversial. Interestingly, current smokers have a significantly reduced risk of developing RP.

\section{Chemotherapy}

Many systemic agents have known pulmonary toxicities (13) and may exacerbate RTinduced injury. The varying drugs, doses and schedules (e.g., sequential, concurrent) make any synthesis of data from multiple studies generally not feasible. Based on general experience, adding chemotherapy should be expected to increase the risk of RP.

Nevertheless, the agents most commonly utilized with RT for lung cancer, such as cisplatin, carboplatin, paclitaxel, and etoposide, have not been consistently shown to increase the risk of pneumonitis $(7,11,14,15,66)$. More modern agents have been associated with high rates of pulmonary toxicity when used concurrently with thoracic RT (e.g., docetaxel and gemcitabine; 1, 16, 64).

\section{Radiation dose-time-fractionation}

RP has a relatively high fractionation sensitivity, the best current estimate $( \pm 1$ standard error of the estimate) of the $\alpha / \beta$ ratio of the linear-quadratic model is $4.0 \pm 0.9 \mathrm{~Gy}$ (65). For comparison, the upper bound on the $95 \%$ confidence interval for $\alpha / \beta$ for pulmonary fibrosis is $3.5 \mathrm{~Gy}$. There is also a significant time factor for pneumonitis, with an overall best estimate of the dose recovered per day, $D_{p}$, of $0.54 \pm 0.21$ Gy/day. Several have suggested methods to adjust the DVH to reflect the impact of fraction size $(6,17)$.

\section{Mathematical/biologic models}

The association between RP risk and MLD (logistic fit to the data in Figure 2B) can be expressed as:

$$
p=\frac{\exp \left(b_{0}+b_{1} \cdot M L D\right)}{1+\exp \left(b_{0}+b_{1} \cdot M L D\right)}
$$

Best fit parameters [95\% confidence intervals] are $\mathrm{b}_{0}=-3.87[-3.33,-4.49], \mathrm{b}_{1}=0.126$ $[0.100,0.153] \mathrm{Gy}^{-1}$. These estimates yield a predicted $\mathrm{TD}_{50}=30.8[28.7,33.9] \mathrm{Gy}$ and $\gamma_{50}$ $=0.97[0.83,1.12]$ (this parameter represents the increase in response [measured in \%] per $1 \%$ increase in dose, near the $50 \%$ dose response level.) A fit using the probit response function (equivalent to a fit of the Lyman model with $\mathrm{n}=1$ ) yields TD50 $=31.4 \mathrm{~Gy}, 95 \%$ conf.: [29.0-34.7 Gy], and $\mathrm{m}=0.4595 \%$ conf.: [0.39-0.51]. The resultant response function is essentially identical to that of the logistic fit in the region occupied by the data. The curvature is slightly smaller, resulting in the slightly larger TD50 value. 


\section{Special situations}

The data reviewed here are largely derived from patients who received partial lung irradiation using conformal 3D-planned external beam RT with conventional fractionation (e.g., 1.8-2.0 Gy/fraction). Several special situations are discussed:

\subsection{Whole Lung Irradiation}

Near-uniform irradiation of both lungs occurs during total body irradiation (TBI) as conditioning for stem cell transplants, hemibody RT for diffuse metastases, and whole lung irradiation (WLI) for prophylaxis or treatment of pulmonary metastases from various malignancies. The risk of RP depends on total dose and fraction size (Fig 3). The development of RP in these settings is an ominous sign, proving fatal in up to $80 \%$ of patients (18). The pathogenesis of RP, in particular after TBI, is relatively complex and depends on multiple patient and treatment-related factors (19). There are consistent data supporting a protective effect of low dose rate and low dose per fraction. For a recent comprehensive review see Sampath (20).

\subsection{Hypofractionation}

Stereotactic body radiation therapy (SBRT) generally involves 1-5 large fractions (e.g. 1430 Gy) given over 5-20 days $(21,22)$. The high-dose volumes are small, and dose gradients are steep, minimizing dose to surrounding critical structures. However, because numerous beams are used, there are large areas of lung receiving low-medium doses (22). Thus, the dose volume characteristics of SBRT are quite different from conventional lung RT, and deserve special consideration. RP is relatively uncommon after SBRT, usually $<10 \%$ (23, $24)$, but as high as $25 \%$ (25). Bronchial injury/stenosis, an unusual complication with conventional doses (26), has been associated with SBRT of perihilar/central tumors (22).

\subsection{Intensity Modulated Radiation Therapy (IMRT) for lung cancer}

M.D. Anderson reported a lower rate of symptomatic grade 23 pneumonitis in 68 patients treated with IMRT, vs. a historical control group of 222 receiving conventional 3D (27). Memorial Sloan Kettering recently noted an acceptable $11 \%$ rate of grade $\geq 3$ pneumonitis in 55 patients treated with IMRT (28). Postoperative IMRT for mesothelioma has been associated with a high rate of lethal pneumontis (8-46\%) (29-31), and extreme care should be used to limit lung irradiation in these cases (see section 8).

\section{Recommended dose/volume limits}

Recommending dose/volume limits is challenging since there are no clear/consistent "thresholds" for candidate metrics (i.e., the response function is often gradual), and the "acceptable" risk level varies with the clinic scenario. RT fields for lung cancer may be appropriately-large for target coverage; physicians and patients often need to accept the significant pulmonary risks. Further, there are marked inter-patient variations in pre-RT lung function that may impact symptom development, and tumor-related dysfunction may improve after RT.

Despite these caveats, it is prudent to limit V20 to $30-35 \%$, and MLD to $\_0-23$ Gy (with conventional fractionation), if one wants to limit the risk of RP to $\_20 \%$, in definitively treated patients with non-small cell lung cancer. Similar guidelines for other parameters can be extracted from the figures. Limiting the dose to the central airways to $\$ 0$ Gy may reduce the risk of bronchial stricture (26). In patients treated post-pneumonectomy for mesothelioma, it is prudent to limit the V5 $<60 \%$, the V20 $<4-10 \%$, and the MLD to $<8$ Gy (see Miles [31] for detailed review). 


\section{Future toxicity studies}

Progress regarding the predictors of RT-induced lung injury requires further understanding of:

a. Endpoint interaction: The study of RT-induced lung injury is confounded by the use of ambiguous endpoints. Many scoring systems combine radiologic, functional, and symptomatic criteria to define a "global score". Since each endpoint may have different dose/volume dependence, this approach maybe counter-productive. Therefore, we recommend that further study of lung injury explicitly consider symptomatic, functional and radiographic endpoints separately.

b. The impact of clinical factors (e.g., pre-RT functional status, tobacco use) and systemic agents (e.g., chemotherapy) on the risk of RP needs further study.

c. Organ interactions: Some data suggest that there may be interactions between the lung and heart in the development of RT-associated dyspnea. In rats, the respiratory rate following thoracic RT was related to the volume of lung and heart irradiated (32-34).

d. The impact of an in situ lung cancer on the risk of radiation-induced lung injury: The data for whole lung radiation is derived essentially from patients without primary lung cancers (e.g., elective lung RT for sarcoma), vs. fractionated partial lung radiation, often derived from patients with gross lung cancers. The confounding effect of tumor in the lung makes the study of RT-induced lung injury extremely challenging. Indeed, in several studies, the ability to predict for RTinduced lung injury is improved in patients without large central/occluding tumors. Thus, it might be relevant to develop separate useful predictive models in patients with intact intra-parenchymal lung tumors vs. those without such a lesion (i.e. postresection RT for lung cancer, or RT for other thoracic tumors).

e. Radiation response modifiers: Amifostine is a thio-organic pro-drug believed to scavenge harmful free radicals mediating RT-induced injury. Several randomized studies in patients receiving RT for lung cancer note a reduction in RP in the amifostine arm although the largest study (from the RTOG) was negative (35). However, this study has been criticized because the drug was administered once daily (4 days/week) and the RT was delivered twice daily (5 days/week), and thus $60 \%$ of the RT fractions were delivered without the protector. Such mixed results, combined with the acute toxicities of amifostine (nausea/vomiting, hypotension, infection, rash), have dissuaded many from using it in routine practice. One small randomized study demonstrated a protective effect of pentoxifylline, but pentoxifylline is not currently utilized in routine clinical practice (36).

f. Biomarkers: Additional work is needed to assess the predictive ability offered by biomarkers such as TGF $\beta$ (measured before and/or during RT).

\section{Toxicity scoring}

A SOMA-LENT-type scoring system is recommended since it explicitly considers symptomatic, functional and radiographic endpoints individually. A global score can be generated, but the granular data can be maintained.

\section{Acknowledgments}

Partially supported by NIH grant 85181 (JOD), NIH grant CA69579 (LBM), and a grant from the Lance Armstrong Foundation (LBM). 


\section{References}

1. Mehta V. Radiation pneumonitis and pulmonary fibrosis in non-small-cell lung cancer: Pulmonary function, prediction, and prevention. Int J Radiat Oncol Biol Phys. 2005; 63:5-24. [PubMed: 15963660]

2. Marks LB, Yu X, Vujaskovic Z, et al. Radiation-induced lung injury. Semin in Radiother Oncol. 2003; 13:333-345.

3. Kocak Z, Evans ES, Zhou S-M, et al. Challenges in defining radiation pneumonitis in patients with lung cancer. Int J Radiat Oncol Biol Phys. 2005; 62:635-638. [PubMed: 15936538]

4. Marks LB, Hollis D, Munley M, et al. The role of lung perfusion imaging in predicting the direction of radiation-induced changes in pulmonary function tests. Cancer. 2000; 88:2135-2141. [PubMed: 10813726]

5. Kwa SL, Lebesque JV, Theuws JC, et al. Radiation pneumonitis as a function of mean lung dose: an analysis of pooled data of 540 patients. Int J Radiat Oncol Biol Phys. 1998; 42:1-9. [PubMed: 9747813]

6. Lebesque JV, Keus RB. The simultaneous boost technique: the concept of relative normalized total dose. Radiotherapy and Oncology. 1991; 22:45-55. [PubMed: 1947212]

7. Graham MV, Purdy JA, Emami B, et al. Clinical dose-volume histogram analysis for pneumonitis after 3D treatment for non-small cell lung cancer (NSCLC). Int J Radiat Oncol Biol Phys. 1999; 45:323-329. [PubMed: 10487552]

8. Yorke ED, Jackson A, Rosenzweig KE, et al. Dose-volume factors contributing to the incidence of radiation pneumonitis in non-small-cell lung cancer patients treated with three-dimensional conformal radiation therapy. Int J Radiat Oncol Biol Phys. 2002; 54:329-339. [PubMed: 12243805]

9. Seppenwoolde Y, De Jaeger K, Boersma LJ, et al. Regional differences in lung radiosensitivity after radiotherapy for non-small-cell lung cancer. Int J Radiat Oncol Biol Phys. 2004; 60:748-758. [PubMed: 15465191]

10. Yorke ED, Jackson A, Rosenzweig KE, et al. Correlation of dosimetric factors and radiation pneumonitis for non-small-cell lung cancer patients in a recently completed dose escalation study. Int J Radiat Oncol Biol Phys. 2005; 63:672-682. [PubMed: 15939548]

11. Hope AJ, Lindsay PE, El Naqa I, et al. Modeling radiation pneumonitis risk with clinical, dosimetric, and spatial parameters. Int J Radiat Oncol Biol Phys. 2006; 65:112-124. [PubMed: 16618575]

12. Bradley JD, Hope A, El Naqa I, et al. A nomogram to predict radiation pneumonitis, derived from a combined analysis of RTOG 9311 and institutional data. Int J Radiat Oncol Biol Phys. 2007; 69:985-992. [PubMed: 17689035]

13. Meadors M, Floyd J, Perry MC. Pulmonary Toxicity of Chemotherapy. Semin in Oncol. 2006; 33:98-105.

14. Robnett TJ, Machtay M, Vines EF, et al. Factors predicting severe radiation pneumonitis in patients receiving definitive chemoradiation for lung cancer. Int J Radiat Oncol Biol Phys. 2000; 48:89-94. [PubMed: 10924976]

15. Hernando ML, Marks LB, Bentel GC, et al. Radiation-induced pulmonary toxicity: a dose-volume histogram analysis in 201 patients with lung cancer. Int J Radiat Oncol Biol Phys. 2001; 51:650659. [PubMed: 11597805]

16. Movsas B, Raffin TA, Epstein AH, et al. Pulmonary radiation injury. Chest. 1997; 111:1061-1076. [PubMed: 9106589]

17. Wheldon TE, Deehan C, Wheldon EG, et al. The linear-quadratic transformation of dose-volume histograms in fractionated radiotherapy. Radiother Oncol. 1998; 46:285-295. [PubMed: 9572622]

18. Fryer CJ, Fitzpatrick PJ, Rider WD, et al. Radiation pneumonitis: experience following a large single dose of radiation. Int J Radiat Oncol Biol Phys. 1978; 4:931-936. [PubMed: 721655]

19. Ozsahin M, Belkacémi Y, Pène Fo, et al. Interstitial pneumonitis following autologous bonemarrow transplantation conditioned with cyclophosphamide and total-body irradiation. Int J Radiat Oncol Biol Phys. 1996; 34:71-77. [PubMed: 12118567] 
20. Sampath S, Schultheiss TE, Wong J. Dose response and factors related to interstitial pneumonitis after bone marrow transplant. Int J Radiat Oncol Biol Phys. 2005; 63:876-884. [PubMed: 16199317]

21. Timmerman RD, Park C, Kavanagh BD. The North American experience with stereotactic body radiation therapy in non-small cell lung cancer. J Thorac Oncol. 2007; 2:S101-112. [PubMed: 17603304]

22. Timmerman R, Galvin J, Michalski J, et al. Accreditation and quality assurance for Radiation Therapy Oncology Group: Multicenter clinical trials using Stereotactic Body Radiation Therapy in lung cancer. Acta Oncol. 2006; 45:779-786. [PubMed: 16982540]

23. Timmerman R, Papiez L, McGarry R, et al. Extracranial stereotactic radioablation: results of a phase I study in medically inoperable stage I non-small cell lung cancer. Chest. 2003; 124:19461955. [PubMed: 14605072]

24. Hara R, Itami J, Komiyama T, et al. Serum levels of KL-6 for predicting the occurrence of radiation pneumonitis after stereotactic radiotherapy for lung tumors. Chest. 2004; 125:340-344. [PubMed: 14718465]

25. Yamashita H, Nakagawa K, Nakamura N, et al. Exceptionally high incidence of symptomatic grade 2-5 radiation pneumonitis after stereotactic radiation therapy for lung tumors. Radiat Oncol. 2007; 2:21. [PubMed: 17553175]

26. Miller KL, Shafman TD, Anscher MS, et al. Bronchial stenosis: an underreported complication of high-dose external beam radiotherapy for lung cancer? Int J Radiat Oncol Biol Phys. 2005; 61:6469. [PubMed: 15629595]

27. Yom SS, Liao Z, Liu HH, et al. Initial Evaluation of Treatment-Related Pneumonitis in AdvancedStage Non-Small-Cell Lung Cancer Patients Treated With Concurrent Chemotherapy and Intensity-Modulated Radiotherapy. International Journal of Radiation Oncology*Biology*Physics. 2007; 68:94-102.

28. Sura S, Gupta V, Yorke E, et al. Intensity-modulated radiation therapy (IMRT) for inoperable nonsmall cell lung cancer: The Memorial Sloan-Kettering Cancer Center (MSKCC) experience. Radiotherapy and Oncology. 2008; 87:17-23. [PubMed: 18343515]

29. Allen AM, Czerminska M, Jänne PA, et al. Fatal pneumonitis associated with intensity-modulated radiation therapy for mesothelioma. Int J Radiat Oncol Biol Phys. 2006; 65:640-645. [PubMed: 16751058]

30. Rice DC, Smythe WR, Liao Z, et al. Dose-Dependent Pulmonary Toxicity After Postoperative Intensity-Modulated Radiotherapy for Malignant Pleural Mesothelioma. Int J Radiat Oncol Biol Phys. 2007; 69:350-357. [PubMed: 17467922]

31. Miles EF, Larrier NA, Kelsey CR, et al. Intensity-Modulated Radiotherapy for Resected Mesothelioma: The Duke Experience. Int J Radiat Oncol Biol Phys. 2008; 71:1143-1150. [PubMed: 18262369]

32. Novakova-Jiresova A, van Luijk P, van Goor H, et al. Pulmonary radiation injury: identification of risk factors associated with regional hypersensitivity. Cancer Res. 2005; 65:3568-3576. [PubMed: 15867350]

33. van Luijk P, Novakova-Jiresova A, Faber H, et al. Radiation Damage to the Heart Enhances Early Radiation-Induced Lung Function Loss. 2005; 65:6509-6511.

34. Wiegman EM, Meertens H, Konings AWT, et al. Loco-regional differences in pulmonary function and density after partial rat lung irradiation. Radiother Oncol. 2003; 69:11-19. [PubMed: 14597352]

35. Movsas B, Scott C, Langer C, et al. Randomized trial of amifostine in locally advanced non-smallcell lung cancer patients receiving chemotherapy and hyperfractionated radiation: radiation therapy oncology group trial 98-01. J Clin Oncol. 2005; 23:2145-2154. [PubMed: 15800308]

36. Ozturk B, Egehan I, Atavci S, et al. Pentoxifylline in prevention of radiation-induced lung toxicity in patients with breast and lung cancer: a double-blind randomized trial. Int J Radiat Oncol Biol Phys. 2004; 58:213-219. [PubMed: 14697441]

37. Ghafoori P, Marks LB, Vujaskovic Z, et al. Radiation-induced lung injury: Assessment, management, and prevention. Oncology. 2008; 22:37. [PubMed: 18251282] 
38. Moiseenko, V.; Deasy, JO.; Dyk, JV. Radiobiological Modeling for Treatment Planning. In: Van Dyk, J., editor. The modern technology of radiation oncology: a compendium for medical physicists and radiation oncologists. Vol. 2. Madison, Wis: Medical Physics Pub; 2005.

39. Rancati T, Wennberg B, Lind P, et al. Early clinical and radiological pulmonary complications following breast cancer radiation therapy: NTCP fit with four different models. Radiother Oncol y. 2007; 82:308-316.

40. Seppenwoolde Y, Lebesque JV, de Jaeger K, et al. Comparing different NTCP models that predict the incidence of radiation pneumonitis. Normal tissue complication probability. Int J Radiat Oncol Biol Phys. 2003; 55:724-735. [PubMed: 12573760]

41. Tucker SL, Liu HH, Wang S, et al. Dose-volume modeling of the risk of postoperative pulmonary complications among esophageal cancer patients treated with concurrent chemoradiotherapy followed by surgery. Int J Radiat Oncol Biol Phys s. 2006; 66:754-761.

42. Kwa SL, Theuws JC, Wagenaar A, et al. Evaluation of two dose-volume histogram reduction models for the prediction of radiation pneumonitis. Radiother Oncol. 1998; 48:61-69. [PubMed: 9756173]

43. Kong FM, Hayman JA, Griffith KA, et al. Final toxicity results of a radiation-dose escalation study in patients with non-small-cell lung cancer (NSCLC): predictors for radiation pneumonitis and fibrosis. Int J Radiat Oncol Biol Phys. 2006; 65:1075-1086. [PubMed: 16647222]

44. Wang S, Liao Z, Wei X, et al. Analysis of clinical and dosimetric factors associated with treatment-related pneumonitis (TRP) in patients with non-small-cell lung cancer (NSCLC) treated with concurrent chemotherapy and three-dimensional conformal radiotherapy (3D-CRT). Int J Radiat Oncol Biol Phys. 2006; 66:1399-1407. [PubMed: 16997503]

45. Martel MK, Ten Haken RK, Hazuka MB, et al. Dose-volume histogram and 3-D treatment planning evaluation of patients with pneumonitis. Int J Radiat Oncol Biol Phys. 1994; 28:575-581. [PubMed: 8113100]

46. Oetzel D, Schraube P, Hensley F, et al. Estimation of pneumonitis risk in three-dimensional treatment planning using dose-volume histogram analysis. Int J Radiat Oncol Biol Phys. 1995; 33:455-460. [PubMed: 7673033]

47. Rancati T, Ceresoli GL, Gagliardi G, et al. Factors predicting radiation pneumonitis in lung cancer patients: a retrospective study. Radiother Oncol. 2003; 67:275-283. [PubMed: 12865175]

48. Kim TH, Cho KH, Pyo HR, et al. Dose-volumetric parameters for predicting severe radiation pneumonitis after three-dimensional conformal radiation therapy for lung cancer. Radiology. 2005; 235:208-215. [PubMed: 15703313]

49. Mao J, Zhang J, Zhou S, et al. Updated assessment of the six-minute walk test as predictor of acute radiation-induced pneumonitis. Int J Radiat Oncol Biol Phys s. 2007; 67:759-767.

50. Schallenkamp JM, Miller RC, Brinkmann DH, et al. Incidence of radiation pneumonitis after thoracic irradiation: Dose-volume correlates. Int J Radiat Oncol Biol Phys. 2007; 67:410-416. [PubMed: 17236964]

51. Tsujino K, Hirota S, Kotani Y, et al. Radiation pneumonitis following concurrent accelerated hyperfractionated radiotherapy and chemotherapy for limited-stage small-cell lung cancer: Dosevolume histogram analysis and comparison with conventional chemoradiation. Int J Radiat Oncol Biol Phys. 2006; 64:1100-1105. [PubMed: 16373082]

52. Koh ES, Sun A, Tran TH, et al. Clinical dose-volume histogram analysis in predicting radiation pneumonitis in Hodgkin's lymphoma. Int J Radiat Oncol Biol Phys. 2006; 66:223-228. [PubMed: 16904523]

53. Piotrowski T, Matecka-Nowak M, Milecki P. Prediction of radiation pneumonitis: dose-volume histogram analysis in 62 patients with non-small cell lung cancer after three-dimensional conformal radiotherapy. Neoplasma. 2005; 52:56-62. [PubMed: 15739028]

54. Fay M, Tan A, Fisher R, et al. Dose-volume histogram analysis as predictor of radiation pneumonitis in primary lung cancer patients treated with radiotherapy. Int J Radiat Oncol Biol Phys. 2005; 61:1355-1363. [PubMed: 15817337]

55. Jenkins P, D’Amico K, Benstead K, et al. Radiation pneumonitis following treatment of non-smallcell lung cancer with continuous hyperfractionated accelerated radiotherapy (CHART). Int J Radiat Oncol Biol Phys. 2003; 56:360-366. [PubMed: 12738310] 
56. Tsujino K, Hirota S, Endo M, et al. Predictive value of dose-volume histogram parameters for predicting radiation pneumonitis after concurrent chemoradiation for lung cancer. Int J Radiat Oncol Biol Phys. 2003; 55:110-115. [PubMed: 12504042]

57. Fu XL, Huang H, Bentel G, et al. Predicting the risk of symptomatic radiation-induced lung injury using both the physical and biologic parameters $\mathrm{V}(30)$ and transforming growth factor beta. Int $\mathrm{J}$ Radiat Oncol Biol Phys. 2001; 50:899-908. [PubMed: 11429217]

58. Marks LB, Munley MT, Bentel GC, et al. Physical and biological predictors of changes in wholelung function following thoracic irradiation. Int J Radiat Oncol Biol Phys. 1997; 39:563-570. [PubMed: 9336133]

59. Armstrong JG, Zelefsky MJ, Leibel SA, et al. Strategy for dose escalation using 3-dimensional conformal radiation therapy for lung cancer. Ann Oncol. 1995; 6:693-697. [PubMed: 8664191]

60. Newton KA. Total thoracic irradiation combined with intravenous injection of autogenous marrow. Clin Radiol. 1960; 11:14-21. [PubMed: 14426843]

61. Newton KA, Spittle MF. An analysis of 40 cases treated by total thoracic irradiation. Clin Radiol. 1969; 20:19-22. [PubMed: 4180118]

62. Salazar OM, Rubin P, Keller B, et al. Systemic (half-body) radiation therapy: response and toxicity. Int J Radiat Oncol Biol Phys. 1978; 4:937-950. [PubMed: 82551]

63. Van Dyk J, Keane TJ, Kan S. Radiation pneumonitis following large single dose irradiation: A reevaluation based on absolute dose to lung. Int J Radiat Oncol Biol Phys. 1981; 7:461-467. [PubMed: 7251416]

64. Onishi H, Kuriyama K, Yamaguchi M, et al. Concurrent two-dimensional radiotherapy and weekly docetaxel in the treatment of stage III non-small cell lung cancer: A good local response but no good survival due to radiation pneumonitis. Lung Cancer. 2003; 40(1):79-84. [PubMed: 12660011]

65. Bentzen SM, Skoczylas JZ, Bernier J. Quantitative clinical radiobiology of early and late lung reactions. Int J Radiat Biol. 2000; 76:453-462. [PubMed: 10815624]

66. Kong FM, Ten Haken R, Eisbruch A, et al. Non-small cell lung cancer therapy-related pulmonary toxicity: an update on radiation pneumonitis and fibrosis. Semin Oncol. 2005; 32:S42-54. [PubMed: 16015535]

67. Yom SS, Liao Z, Hu C, et al. Preliminary Report of Radiation Pneumonitis (RP) in Patients with Non-Small Cell Lung Cancer (NSCLC) Treated with Intensity Modulated Radiotherapy (IMRT) and Concurrent Chemotherapy (ConChT). International Journal of Radiation Oncology*Biology*Physics. 2005; 63:S407.

68. Willner J, Jost A, Baier K, et al. A little to a lot or a lot to a little? An analysis of pneumonitis risk from dose-volume histogram parameters of the lung in patients with lung cancer treated with 3-D conformal radiotherapy. Strahlenther Onkol. 2003; 179:548-556. [PubMed: 14509954]

69. Kim TH, Cho KH, Pyo HR, et al. Dose-volumetric parameters for predicting severe radiation pneumonitis after three-dimensional conformal radiation therapy for lung cancer. Radiology. 2005; 235:208-215. [PubMed: 15703313]

70. Vogelius, S.; Bentzen, SM. Risk factors for development of radiation induced pneumonitis. (submitted) 


\begin{tabular}{|c|c|c|}
\hline Study & $\begin{array}{c}\text { Lyman n } \\
\text { IV, Fixed, } 95 \% \mathrm{CI}\end{array}$ & $\begin{array}{c}\text { Lyman n } \\
\text { IV, Fixed, 95\% CI }\end{array}$ \\
\hline Moiseenko 2003 & $1.02[0.02,2.02]$ & \\
\hline Seppenwoolde 2003 & $0.99[0.60,1.38]$ & \\
\hline Tucker 2006 & $1.85[0.04,3.66]$ & \\
\hline Total $(95 \% \mathrm{CI})$ & $1.03[0.67,1.39]$ & \\
\hline \multirow[t]{2}{*}{ Heterogeneity: } & $P=0.66 ; I^{2}=0 \%$ & $\begin{array}{lll}1 & 1 & 1 \\
0 & 1 & 2\end{array}$ \\
\hline & & Lyman n \\
\hline
\end{tabular}

Figure 1.

Meta-analysis of reported $n$-values (volume parameter) for the LKB model using an inversevariance (IV) weighting method. Recovery of variance estimates from the $95 \%$ confidence intervals (CI) and use of $\sim \pm 2 *$ sigma instead of $1.96 *$ sigma gave rise to small deviations in the derived $95 \% \mathrm{CI}$ as compared to the literature reported values. Data estimated from (38, 40-41). Abbreviations: $\mathrm{n}=n$-values for the LKB Model, IV $=$ inverse variance, Fixed $=$ fixed effect model $\mathrm{CI}=$ confidence interval. The $n$ value reflects the manner in which dose/ volume parameters lead to complications. A lower value of $n$ suggests that the tissue is sensitive to hot spots (e.g., an organ structured in "series"), while a higher value of $n$ (closer to 1.0), suggests that the risk is more related to the volume of an organ irradiated (e.g., "parallel" structure). 

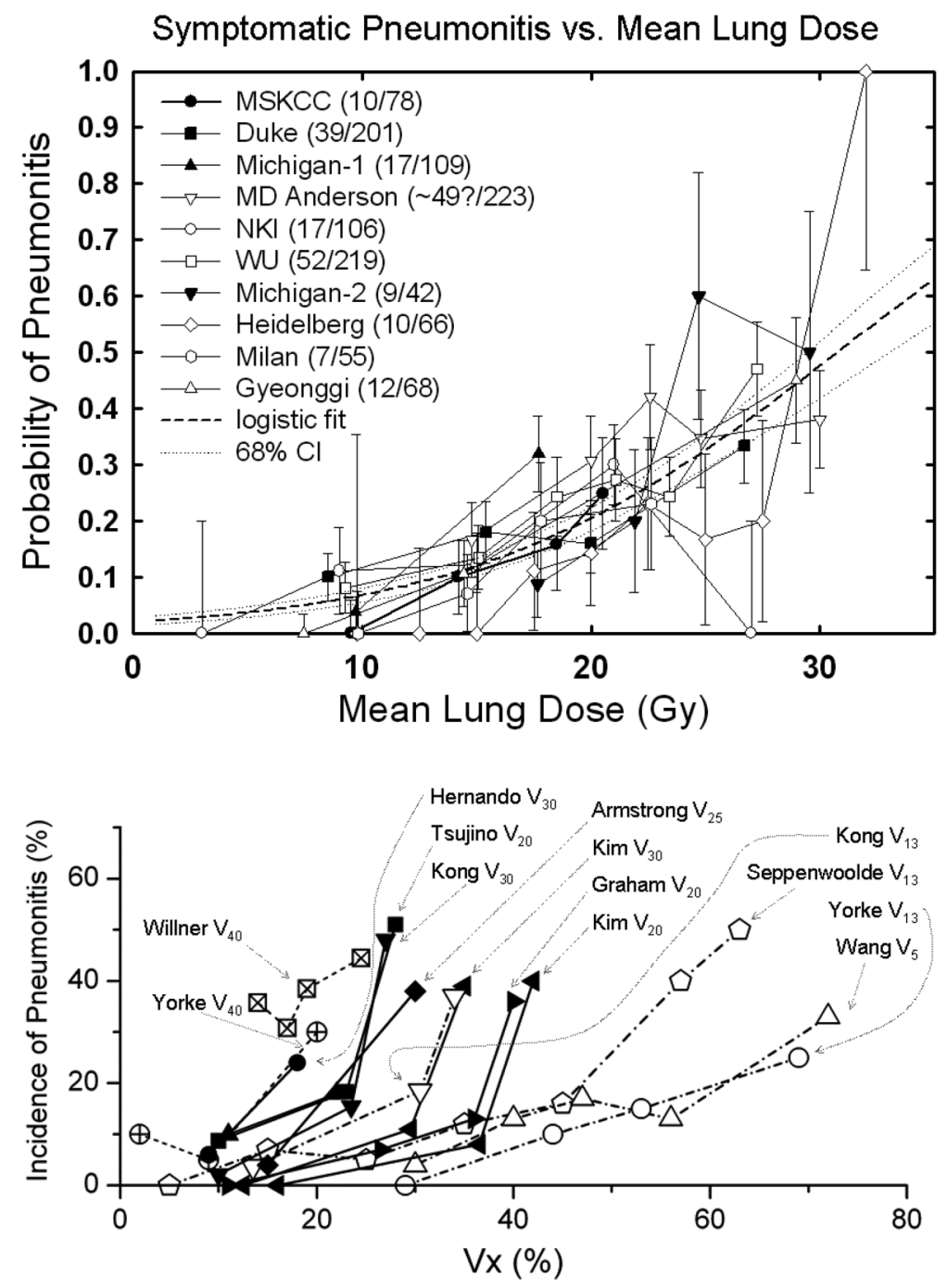

Figure 2.

Rate of RP following fractionated partial lung RT related to:

Panel A: Mean lung dose. Confidence intervals shown are \pm 1 standard deviation.

.Mean dose response data from: MSKCC, (10) from Fig 4a; ( RTOG grade 3, 6 months); Duke, (15) from Table 4; ( $\geq$ CTC grade 1, 6 months); Michigan, (43) from Table 4 and Fig 2a; ( $\geq$ SWOG grade 2, 6 months) - bin location and time from authors; MD Anderson, (44) from Fig 2; ( $\geq$ CTC grade 3, 1 year actuarial-includes concurrent chemo patients); NKI, (9) from Fig 3a; ( 2 SWOG grade 2, 6 months); Washington University, (11) from Fig 9c; ( $\geq \mathrm{SWOG}$ grade 2-no time limit) with bin locations from authors, increased by $11 \%$ to account for inhomogeneity corrections; Michigan, (45) from Table 1; ( ¿SWOG grade 1) with mean doses calculated from relationship between EUD $(n=0.87)$ and mean dose from

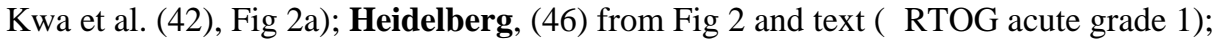
Milan, (47) from Fig 3; ( 2 SWOG Grade 2-no time limit, patients without COPD includes induction chemo patients); Gyeonggi, (48) from Table 5; ( $\mathbb{R}$ TOG grade 3, 6 months_-includes concurrent chemo patients) - median values of mean dose in each bin provided by the authors. Dashed line is logistic fit: data fit to the form $(f /(1+f))$, where $\mathrm{f}=\exp (\mathrm{b} 0+\mathrm{b} 1 * \mathrm{dmean})$. Best fit values [95\% confidence intervals] are $\mathrm{b} 0=-3.87[-3.33-$ $-4.49], \mathrm{b} 1=0.126[0.100-0.153]$, corresponding to $\mathrm{TD}_{50}=30.75[28.7-33.9]$ Gy and $\gamma_{50}=$ 
0.969 [0.833-1.122], where $\gamma_{50}$ represents the increase in response [measured in $\%$ ] per $1 \%$ increase in dose, near the $50 \%$ dose response level.

Panel B: The rate of RP is shown for different values of Vx.

$\mathrm{V}_{\mathrm{x}}$ response data from: Yorke $\mathrm{V}_{13}, \mathrm{~V}_{40}$, (10) from Fig 4d; Willner $\mathrm{V}_{40}$, (68) from Fig 4;

Hernando $V_{30}$, (15) from Table 6; Tsujino $V_{20}$, (56) from Fig 1; Kong $V_{13}, V_{20}$, (43), from Table 4; Armstrong $V_{25}$, (59) Fig 3; Kim $V_{20}, V_{30}$, (69) from Table 5; Graham $V_{20}$, (7) from Table 4; Seppenwoolde $V_{13}$, (40) from Fig 2; Wang $V_{5}$, (44). Some data estimated from published reports. 


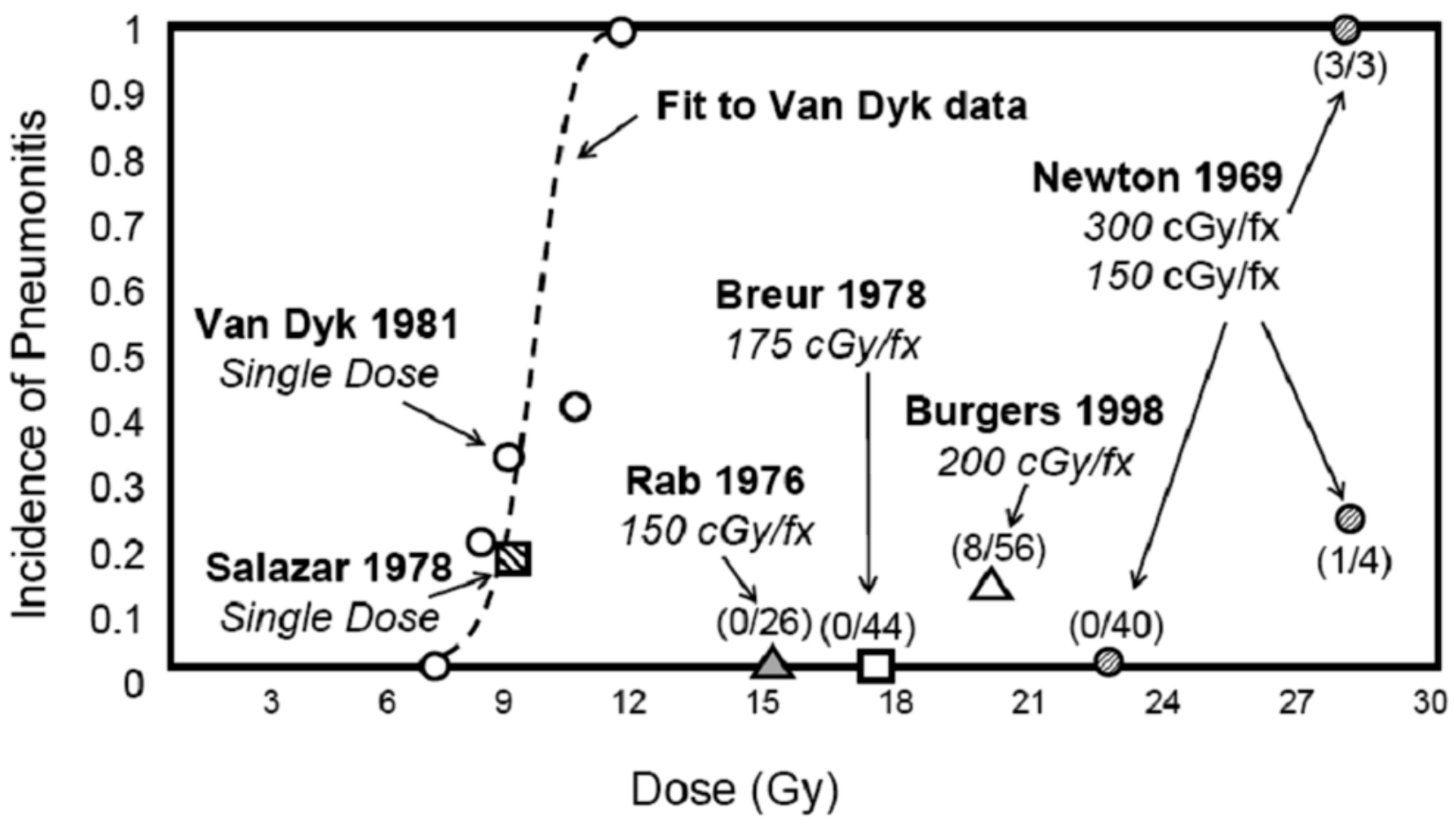

Figure 3.

Whole lung irradiation for diffuse lung or boney metastases, or prophylaxis for occult metastatic disease $(18,60-63)$. Numbers in parentheses give the incidence of pneumonitis divided by the population at risk for each fractionation scheme in each study. Some data estimated from published reports. 
Table 1

Example end points for RT-induced lung injury (and approximate incidence)

\begin{tabular}{|c|c|c|}
\hline & Regional & Global \\
\hline Clinical & Bronchial stricture $\left(<3 \%{ }^{*}\right)$ & Shortness of breath $(5-50 \%)$ \\
\hline Subclinical & $\begin{array}{l}\text { Radiologic abnormalities (e.g. computed tomography, } \\
\text { perfusion/ventilation scans) (20-80\%) }\end{array}$ & $\begin{array}{l}\text { Pulmonary Function Tests, Six-minute Walk Test, Blood } \\
\text { gases, exercise capacity } \#\end{array}$ \\
\hline
\end{tabular}

Example endpoints used to study RT-induced lung injury can be broadly segregated as shown.

*

Uncommon with conventional fractionation and doses. More common with brachytherapy, high total doses and/or hypofractionation.

\# Many patients experience declines in functional assessments, but the magnitude of the decline is variable. 